\title{
ПОВЕДЕНИЕ СОСНЯКОВ КАК ЭРГАТИЧЕСКОЙ СИСТЕМЫ
}

(по данным J. Ilvessalo из книги А. К. Каяндера о лесах Южной Финляндии)

Мазуркин Петр Матвеевич

доктор технических наук, профессор, академик ЕАЕ, РАE и РАEН Поволжский государственный технологический университет, г. Йошкар-Ола

\section{BEHAVIOUR OF PINE FORESTS AS ERGATIC SYSTEM}

(according to J. Ilvessalo from A.K. Kayander's book about the woods of the Southern Finland)

Mazurkin Peter Matveevich

Doctor of Engineering Science, Academician of RANS, member of EANS, Volga State University of Technology, Yoshkar-Ola, Russia, E-mail: kaf po@mail.ru

Аннотация. С учетом живого вещества лесов лесное хозяйство является эргатической системой. Даны статистические закономерности с колебаниями прямого вмешательства человека (по таблице Ilvessalo и А. К. Каяндера хода роста) на динамику роста сосняков по запасу стволовой древесины в коре на 241 пробной площади из Южной Финляндии 1916-1918 гг. Первое ограничение извлечению из леса кругляка было по толщине ствола. Для моделирования объединены две таблицы и дополнительно дана доля запаса древесины, рекомендуемая Ilvessalo и А. К. Каяндером к извлечению из сосняков.

\begin{abstract}
In view of living matter forest forestry is ergatic system. Given statistical trends to fluctuations direct human intervention (table Ilvessalo and A.K. Kayander of the growth) on the dynamics of pine on stem volume in the crust at 241 sampling area of southern Finland 1916-1918. The first limitation of harvesting timber logs was the thickness of the trunk. To model combines two tables, and additionally given the share of timber resources, and recommended Ilvessalo A.K. Kayander to extract from pine.
\end{abstract}

Ключевые слова: сосняки, типы леса, динамика запаса, волновые закономерности Keywords: pine, forest types, the dynamics of the stock, the wave patterns

Введение. В общем смысле под эргатической будем понимать систему с учетом живого вещества (понятия живого и косного вещества по В.И. Вернадскому). В частном случае эргатическая система - это также система с включением людей, например, лесное хозяйство.

Простейшей эргатической структурой является модель «человек-машина», и в ней безоговорочно первично поведение человека-оператора. Лесной «специалист» (по Далю - лесомыга) ведет себя механистически в лесу: его учили по проф. М. М. Орлову [10], что лес - это фабрика, а лесное дерево - машина по производству древесины. И он всячески пытается управлять лесными деревьями. Часто не получается: не знает законы поведения древостоев.

Интересно выразился М. М. Орлов [10] «лес есть пространство, покрытое деревьями, растущими в сообществе», критикуя В. И. Даля [1], у которого ««лес есть пространство, покрытое растущими и рослыми деревьями». Но в словаре Даля основатель лесной экономии не учел еще 29 определений, дающих живые черты самому лесу и людям, обитающим в лесу. Причем В. И. Даль 
[1, с.367] четко понимал «растущее» как «здоровое». Таким образом, до начала XX века (словарь 1903-1909 гг.) слово «лес» имело большое разнообразие понятий. Здесь были и географические понятия. Многие функциональные определения относятся только к деревьям. За сто лет активного и интенсивного пользования лесом как поделочной древесиной словарный запас В. И. Даля во много раз сократился.

Термин «хозяйственный лес» закрепил проф. Г. Ф. Морозов в своем учении о лесе [9]. Академик И. С. Мелехов указывает [2, с.7], что Г. Ф. Морозов требовал от лесоводов принимать во внимание и другие лесоводственные свойства - почву и климат, прямое и косвенное вмешательство человека в жизнь леса (отмечено нами - П. М.).

Цель статьи - дать закономерности прямого вмешательства человека (по таблице Ilvessalo и А. К. Каяндера хода роста сосняков [3]) на динамику роста древостоев по запасу стволовой древесины в коре на 241 пробной площади из Южной Финляндии 1916-1918 гг.

Концепция идентификации. Прямое вмешательство в жизнь леса было всегда через извлечение из него кругляка. Первое ограничение этому процессу - по толщине ствола.

При понятии «рослое» значение толщины В. И. Даль не уточняет. Однако известно, что в 1703 г. минимальная толщина ствола была 12 вершков $(53,3 \mathrm{~cm})$ в верхнем отрубе (указ Петра I). В брошюре А. К. Каяндера [3] - уже только 28 см. Поэтому определение леса как древостоя у Даля весьма практичное. Оно содержит: функциональное (рослый и здоровый, а также лес строевой, дровяной, поделочный, мачтовый и пр.); конструктивное (крупные бревна из стволов у комля $\geq 70$ см при Петре I); параметрическое (значение толщины со временем снижалось, достигнув 28 см в [3], а теперь по европейскому стандарту равно 4 см).

Исходные данные. В таблице 1 нами объединены две таблицы из [3] и дополнительно дана доля запаса, рекомендуемая к извлечению. При этом по таблице Ilvessalo хода роста сосняков (первая часть таблицы 1) нами были выявлены закономерности с колебаниями.

Тогда получается, что финский лесовод Ilvessalo, а вслед за ним и А. К. Каяндер, сознательно завершили верхнюю границу возраста сосняков на уровнях 120 лет (типы леса ОМТ и МT), 130 лет (тип леса VT) и 150 лет (типы леса СТ и СІТ).

Такой прием привычен для лесопромышленников [8]. Однако такое ограничение недопустимо в лесной науке, так как предельный возраст сосен в сосняках Сибири достигает 464 года.

В итоге лесная типология А. К. Каяндера [3], как выясняется, относится только к хозяйственным соснякам. Но сами сосняки 1916-1918 гг., в которых Ilvessalo проводил измерения на 241 пробной площади и на стольких же модельных соснах господствующего класса высоты, несомненно, относятся к древостоям естественного происхождения. Если бы у нас были для информацион- 
ной обработки первичные данные всех измерений, причем без всякой их группировки, то мы бы сразу же перешли к ним, отбросив таблицу 1 как отображение личных взглядов Ilvessalo и Каяндера.

Таблица 1

- Запас деловой древесины в коре в стволах диаметром 28 см и более на высоте 1,3 м в нормальных сосняках (по Ilvessalo) $[1, \mathrm{c.35}], \mathrm{m}^{3} / \mathbf{r a}$

\begin{tabular}{|c|c|c|c|c|c|c|c|c|c|c|c|c|c|c|c|}
\hline \multirow{2}{*}{$\begin{array}{c}\text { Возраст } \\
A, \text { лет }\end{array}$} & \multicolumn{1}{|c|}{ Запас по типам леса, ${ }^{3}$} & МТ & VT & СТ & CIT & OMT & MT & VT & CT & CIT & OMT & MT & VT & СТ & СIT \\
\hline 10 & 19 & 13 & 10 & 7 & - & - & - & - & - & - & - & - & - & - & - \\
\hline 20 & 70 & 60 & 44 & 24 & 3 & - & - & - & - & - & - & - & - & - & - \\
\hline 30 & 140 & 135 & 87 & 47 & 10 & - & - & - & - & - & - & - & - & - & - \\
\hline 40 & 208 & 200 & 134 & 75 & 17 & - & - & - & - & - & - & - & - & - & - \\
\hline 50 & 279 & 260 & 177 & 104 & 31 & 15 & - & - & - & - & 5.38 & - & - & - & - \\
\hline 60 & 344 & 313 & 219 & 128 & 46 & 63 & 21 & - & - & - & 18.31 & 6.71 & - & - & - \\
\hline 70 & 405 & 363 & 262 & 153 & 62 & 145 & 63 & 12 & - & - & 35.80 & 17.36 & 4.58 & - & - \\
\hline 80 & 458 & 407 & 299 & 178 & 80 & 229 & 132 & 43 & - & - & 50.0032 .43 & 14.38 & - & - \\
\hline 90 & 500 & 443 & 328 & 203 & 98 & 287 & 200 & 86 & - & - & 57.40 & 45.15 & 26.22 & - & - \\
\hline 100 & 535 & 472 & 351 & 222 & 114 & 319 & 248 & 130 & 6 & - & 59.63 & 52.54 & 37.04 & 2.70 & - \\
\hline 110 & 560 & 492 & 366 & 240 & 132 & 348 & 273 & 158 & 7 & - & 62.1455 .49 & 43.17 & 2.92 & - \\
\hline 120 & 576 & 503 & 375 & 254 & 148 & 375 & 292 & 178 & 37 & - & 65.1058 .05 & 47.47 & 14.57 & - \\
\hline 130 & - & - & 382 & 266 & 164 & - & - & - & - & - & - & - & - & - & - \\
\hline 140 & - & - & - & 275 & 180 & - & - & - & - & - & - & - & - & - & - \\
\hline 150 & - & - & - & 282 & 195 & - & - & - & - & - & - & - & - & - & - \\
\hline
\end{tabular}

Но первичных данных измерений у нас нет, поэтому примем таблицу 1.

Хозяйственная часть сосняков. Динамика хода роста сосен толщиной не менее 28 см на высоте 1,3 м рассмотрена по каждому типу леса. Для сопоставления с общей таблицей хода роста для разрешенных к извлечению стволовой древесины сосен принят новый шифр.

Для типа леса ОМТ28 тренд получает (рис. 1) биотехнический закон вида

$$
V_{\geq 28}=-78,82662 \exp (-0,0040945 A)+1,90155 \cdot 10^{-10} A^{11,83927} \exp \left(-3,85445 A^{0,41617}\right) \text {. }
$$

Аналогично двухчленные уравнения получены и для других типов леса:

- типа леса МТ28

$V_{\geq 28}=-31,49497 \exp (-0,0034044 A)+1,43151 \cdot 10^{-20} A^{18,43335} \exp \left(-3,32589 A^{0,50226}\right)$;

- тип леса VT28

$V_{228}=-18,39349 \exp (-0,0011365 A)+1,07831 \cdot 10^{-29} A^{27,80117} \exp \left(-7,21946 A^{0,44622}\right)$;

- тип леса СТ28 $V_{\geq 28}=5,66721+4,70819 \cdot 10^{-70} A^{34,06274}$.

Из рисунка 1 видно, что тип леса СТ является явно недоразвитым, при этом по всем типам леса А. К. Каяндеру нужно было продолжить группы возраста $A$ далее 150 лет, а в каждой 10-летней группе возраста намечать выборочное, а не сплошное, извлечение древесины из древостоев, как это было выполнено у Тюрмера за 50 лет по его брошюре 1890 г.

Первые три уравнения показывают, что в хозяйственных сосняках (табл. 2) имеются характерные моменты при ежегодном представлении групп $A$ в интервале $t=0-200$ лет. 

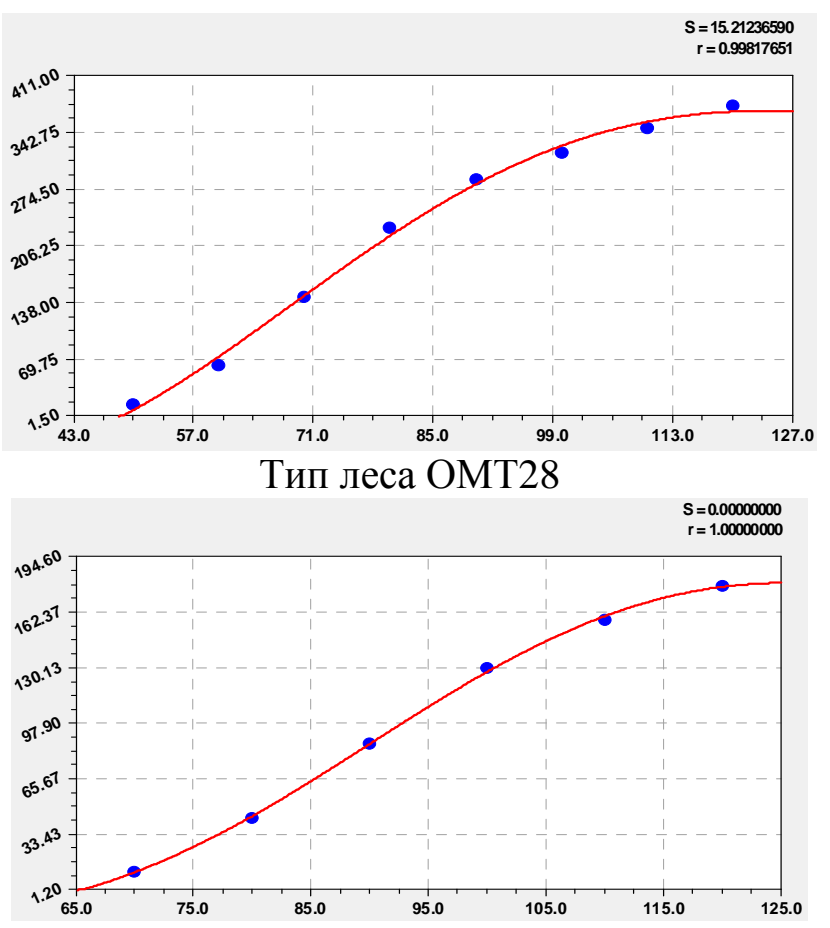

Тип леса VT28

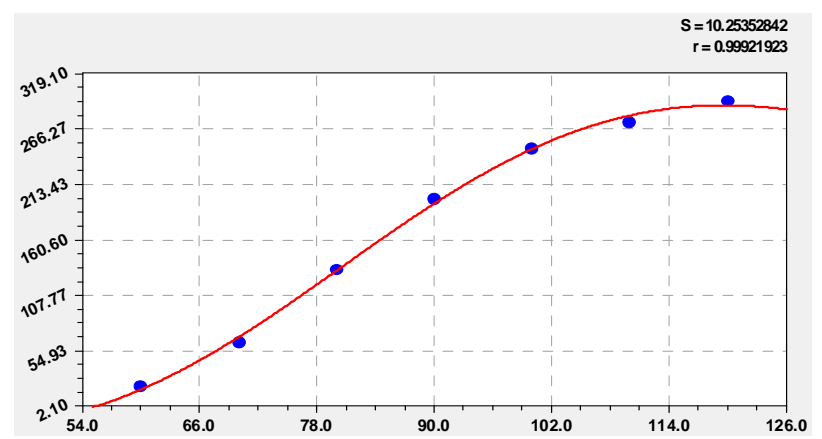

Тип леса МТ28

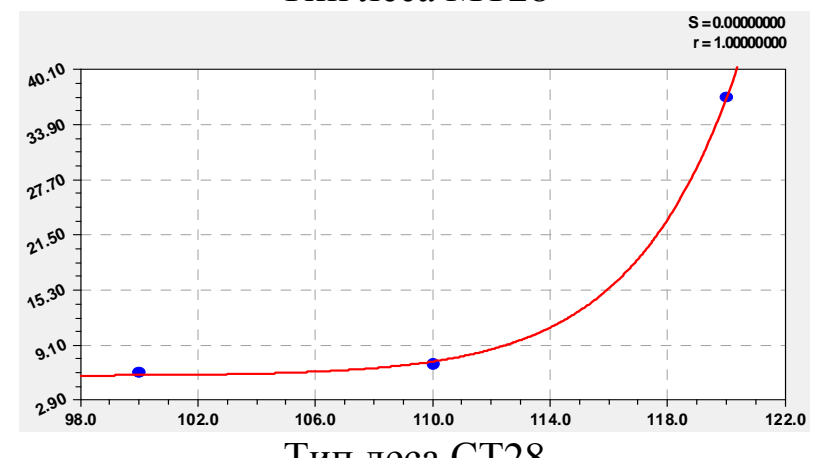

Тип леса СТ28

Рис. 1. Тренды динамики разрешенного к извлечению из разных типов леса запаса стволовой древесины, $\mathrm{m}^{3} /$ га

Таблица 2

Извлекаемый запас, $\mathrm{m}^{3} /$ га

\begin{tabular}{|c|c|c|c|}
\hline Возраст & \multicolumn{3}{|c|}{ Тип леса при $D \geq 28 \mathrm{~cm}$} \\
\cline { 2 - 4 }$t$, лет & OMT & MT & VT \\
\hline 0 & $-78,8$ & $-31,5$ & $-18,4$ \\
\hline 49 & 3,7 & - & - \\
\hline 55 & - & 0,8 & - \\
\hline 65 & - & - & 0,2 \\
\hline 120 & - & 289,3 & - \\
\hline 124 & 369,0 & - & - \\
\hline 125 & - & - & 179,7 \\
\hline 200 & 183,2 & 64,1 & 30,8 \\
\hline
\end{tabular}

До возраста 49...65 лет сосняки как бы живут в долг человеку, хотя они никак не обязаны это делать. В этот период возможно извлечение из леса хвороста, жердей и других лесоматериалов. Намеченная в таблице 1 хозяйственная часть сосняков может дать максимальный объем запаса кругляка в 120-125 лет.

Но древостои произрастают циклически годами, а не по десятилетиям, поэтому расчеты по уравнениям до возраста 200 лет показывают, что при выборочной рубке отдельных деревьев вполне возможен некий запас и «неделовой» древесины.

Доля хозяйственной части сосняков. Этот показатель $\alpha$ характеризует активность вмешательства лесовода в жизнедеятельность леса при извлечении кругляка по таблице 1.

После идентификации получено:

- для типа леса ОМТ28

$$
\alpha_{28}=96,94194 \exp (-0,0033806 A)-127,7197 \exp \left(-2,97571 \cdot 10^{-5} A^{2,48533}\right) ;
$$

- для типа леса МТ28

$$
\alpha_{28}=388,8377 \exp (-0,013898 A)-279,8351 \exp \left(-3,03451 \cdot 10^{-5} A^{2,39054}\right) ;
$$

- для типа леса VT28

$$
\alpha_{28}=432,6838 \exp (-0,013998 A)-292,6369 \exp \left(-2,81509 \cdot 10^{-5} A^{2,35183}\right) .
$$



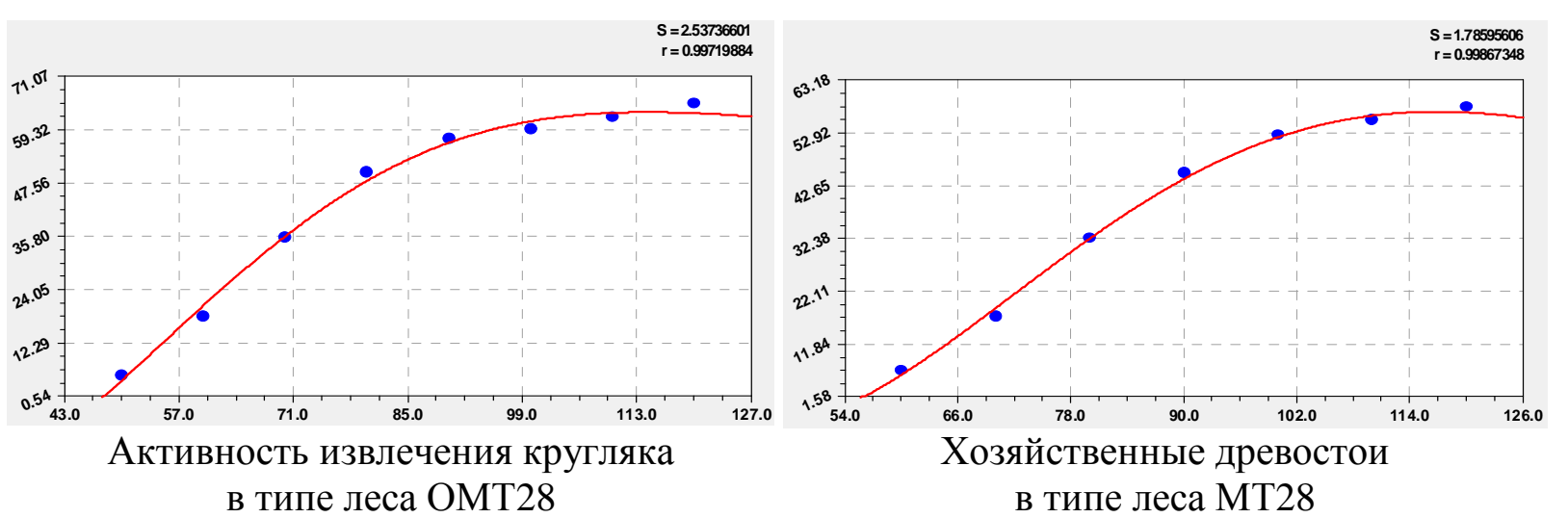
в типе леса ОМТ28

Эти формулы показывают борьбу двух сил, причем со временем обе убывают по закону гибели: во-nервых, сила развития и роста древостоя по запасу древесины ствола; во-вторых, кризисное извлечение человеком кругляка из леса рубками деревьев и древостоев.

После расчетов в Excel в таблице 3 даны характерные моменты годичного извлечения.

Хозяйственные древостои в типе леса МТ28

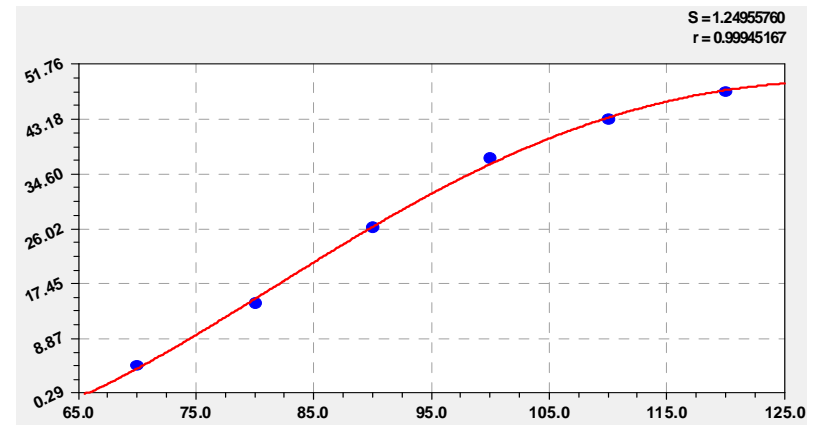

Хозяйственные сосняки в типе леса VT28

Рис. 2. Тренды динамики доли разрешенного к извлечению из леса запаса стволовой древесины, \%

В период 0-39 лет в типе леса ОМТ извлечение является отрицательным, и здесь потребности человека кризисные: лесоводы, составившие таблицу 1 хода роста и извлечения кругляка из хозяйственных сосняков, перестарались. При этом типы леса МТ и VT показывают положительную долю, но она явно не относится к кругляку, а только к хворосту и жердям.

В период 48-66 лет, в трех типах леса поразному, возможен отпуск сосняков на стволы диаметром не менее 28 см. При этом максимумы извлекаемого запаса кругляка находятся в интервале возраста древостоя 114-131 год.

По уравнениям даже в 200 лет из сосняков можно извлекать стволы 28 см и более, но, по-видимому,

Таблица 3

Доля извлечения, \%

\begin{tabular}{|c|c|c|c|}
\hline \multirow{2}{*}{$\begin{array}{c}\text { Возраст } \\
t, \text { лет }\end{array}$} & \multicolumn{3}{|c|}{ Тип леса при } \\
\cline { 2 - 4 } & OMT & MT & VT \\
\hline 0 & $-30,8$ & 109,0 & 140,0 \\
\hline 32 & - & 1,1 & - \\
\hline 39 & - & - & 0,1 \\
\hline 48 & 0,9 & - & - \\
\hline 55 & - & 0,7 & - \\
\hline 66 & - & - & 0,5 \\
\hline 114 & $\mathbf{6 3 , 2}$ & - & - \\
\hline 117 & - & 57,1 & - \\
\hline 131 & - & - & 49,2 \\
\hline 200 & 49,3 & 24,1 & 26,1 \\
\hline
\end{tabular}
уже не как деловую древесину.

Не извлекаемая по кругляку часть сосняков. Данные для статистического моделирования приведены в таблице 4 .

Ряды хода роста по двум типам леса ОМТ и МТ являются не завершенными. При этом тип леса СТ, из-за трех групп возраста по извлечению стволов не менее 28 см на высоте 1,3 м, мало меняет исходную закономерность, но только нарушает её.

На рисунке 3 даны графики изменения остаточного запаса древесины по типам леса ОМТ, МТ и VT. 
Запас оставшейся древесины в коре стволами $<28$ см

\begin{tabular}{|c|c|c|c|c|c|c|c|c|c|c|c|c|}
\hline \multirow{2}{*}{$\begin{array}{c}\text { Возраст } \\
A, \text { лет }\end{array}$} & \multicolumn{5}{|c|}{ по типам леса, м³/га } & \multicolumn{3}{|c|}{ до $28 \mathrm{~cm}, \mathrm{~m}^{3} / г а$} & \multicolumn{4}{|c|}{ Доля до 28 см, \% } \\
\hline & OMT & MT & VT & $\mathrm{CT}$ & OMT & MT & VT & $\mathrm{CT}$ & OMT & MT & VT & $\mathrm{CT}$ \\
\hline 10 & 19 & 13 & 10 & 7 & 19 & 13 & 10 & 7 & 100 & 100 & 100 & 100 \\
\hline 20 & 70 & 60 & 44 & 24 & 70 & 60 & 44 & 24 & 100 & 100 & 100 & 100 \\
\hline 30 & 140 & 5 & 87 & 47 & 140 & 135 & 87 & 47 & 100 & 100 & 100 & 00 \\
\hline 40 & 208 & 200 & 134 & 75 & 208 & 200 & 134 & 75 & 100 & 100 & 100 & 100 \\
\hline 50 & 279 & 260 & 177 & 104 & 264 & 260 & 177 & 104 & 94,62 & 100 & 100 & 100 \\
\hline 60 & 344 & 313 & 219 & 128 & 281 & 292 & 219 & 128 & 81,69 & 93,29 & 100 & 100 \\
\hline 70 & 405 & 363 & 262 & 153 & 260 & 300 & 250 & 153 & 64,20 & 82,64 & 95,42 & 100 \\
\hline 80 & 458 & 407 & 299 & 178 & 229 & 275 & 256 & 178 & 50,00 & 67,57 & 85,62 & 100 \\
\hline 90 & 500 & 443 & 328 & 203 & 213 & 300 & 242 & 203 & 42,60 & 67,72 & 73,78 & 100 \\
\hline 100 & 535 & 472 & 351 & 222 & 216 & 224 & 221 & 216 & 40,37 & 47,46 & 62,96 & 97,30 \\
\hline 110 & 560 & 492 & 366 & 240 & 212 & 219 & 208 & 233 & 37,86 & 44,51 & 56,83 & 97,08 \\
\hline 120 & 576 & 503 & 375 & 254 & 201 & 213 & 197 & 217 & 34,90 & 42,35 & 52,53 & 85,43 \\
\hline 130 & - & - & 382 & 266 & - & 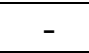 & 382 & 266 & - & - & 100 & 100 \\
\hline 140 & - & - & - & 275 & - & - & - & 275 & - & - & - & 100 \\
\hline 150 & - & - & - & 282 & - & - & - & 282 & - & - & - & 100 \\
\hline
\end{tabular}

Параметры у выявленных закономерностей приведены в таблице 5.

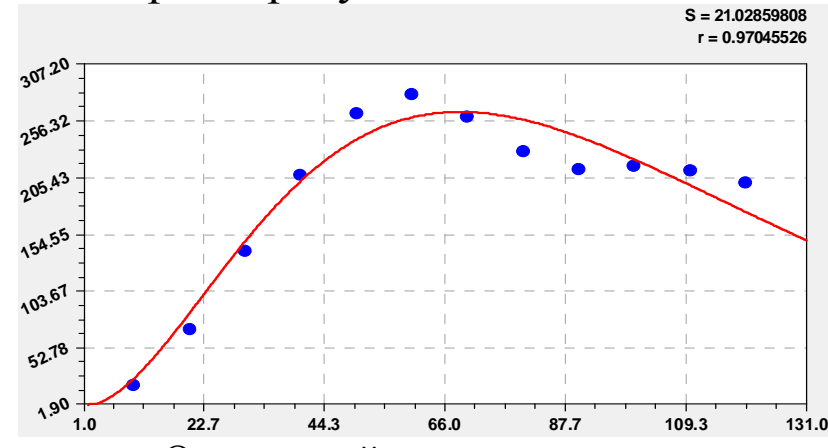

Остаточный запас древесины в типе леса ОМТ28

На графиках видны колебательные возмущения оставляемого после рубок запаса. Этот факт четко указывает, что сосняки после рубок подвергаются сильным колебаниям. Завершенность антропогенного влияния проявляется только у типа леса VT.

По оставляемому, после проведения рубок деревьев и древостоев, запасу можно оценивать даже до проведения рубок, и особенно для контроля после рубок, не только экологическую, но и хозяйственную в будущем добротность расстроенных рубками лесов.

На рисунке 4 показаны графики динамики доли оставляемого запаса от исходного запаса древесины. 

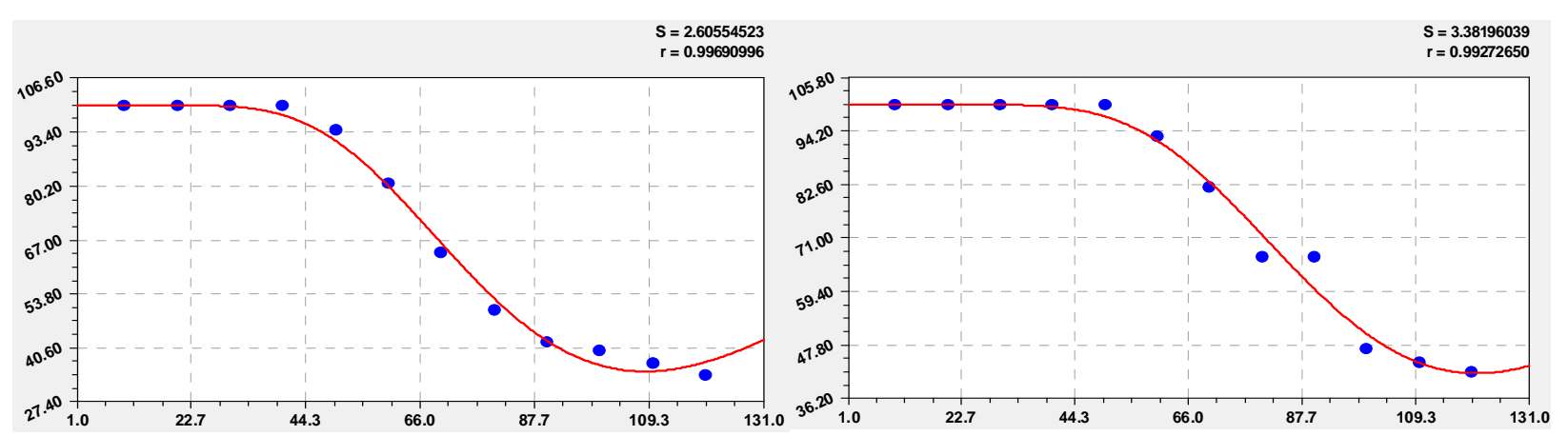

Доля остаточного запаса в типе леса ОМТ28

Завершенным является только ряд хода роста по типу леса VT. После анализа формул можно будет рассмотреть волновую составляющую $\alpha=f(t)$ по типу леса VT.

Общая биотехническая закономерность. Индуктивно, на основе десятков тысяч примеров идентификации статистических выборок из различных областей науки и техники, Доля остаточного запаса в типе леса МТ28

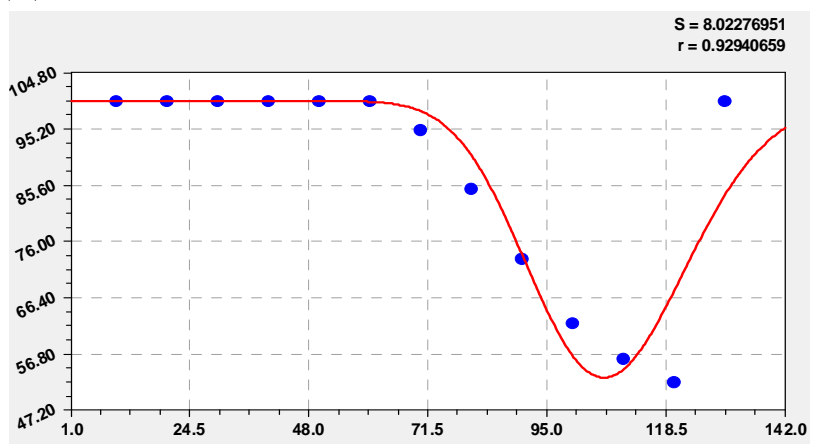

Доля остаточного запаса в типе леса VT28

Рис. 4. Динамика доли остаточного запаса древесины нами были выявлены всего две обобщенные математические модели, которые в общем математическом виде словесно формулируются так:

а) обобщенная детерминированная (трендовая) модель для дедуктивной идентификации по значениям факторов и связей между ними;

б) общая волновая функция в виде формулы асимметричного вейвлетсигнала.

Причем первая группа является только частным случаем второй группы, содержащей в выявленных биотехнических закономерностях тренды и колебательные возмущения.

Было выявлено, если антропогенное влияние незначительное, то природные объекты ведут себя колебательным возмущением позитивно и адаптивно к окружающей среде. Как правило, только человек вводит в природные процессы негативные колебательные возмущения. Природные катастрофы влияют на лесные участки совершенно иным образом.

Любые детерминированные тенденции моделируются идентификацией с использованием двухчленной биотехнической закономерности вида

$$
y=a_{1} x^{a_{2}} \exp \left(-a_{3} x^{a_{4}}\right)+a_{5} x^{a_{6}} \exp \left(-a_{7} x^{a_{8}}\right),
$$

где $y$ - оценочный параметр (параметр - это показатель, характеризующий систему),

$x$ - влияющий параметр, в нашем примере возраст $A$ или $t$, лет.

В таблицах 5 и 6 приведены матричные формы для компактной записи значений параметров общей модели (8) по всем выявленным предыдущим закономерностям. 
Параметры формулы влияния возраста на запас и долю извлекаемой рубками $\geq 28$ см части сосняков

\begin{tabular}{|c|l|c|c|c|c|c|c|c|c|c|}
\hline Тип & Связь & \multicolumn{2}{|c|}{ Первая составляющая } & \multicolumn{4}{c|}{ Вторая составляющая } & Коэф. \\
\cline { 2 - 12 } леса & $x \rightarrow y$ & $a_{1}$ & $a_{2}$ & $a_{3}$ & $a_{4}$ & $a_{5}$ & $a_{6}$ & $a_{7}$ & $a_{8}$ & корр. \\
\hline \multirow{2}{*}{ OMT28 } & $A \rightarrow V$ & $-78,82662$ & 0 & 0,0040945 & 1 & $1,90155 \mathrm{e}-10$ & 11,83927 & 3,85445 & 0,41617 & 0,9982 \\
\cline { 2 - 13 } & $A \rightarrow \alpha$ & 96,94194 & 0 & 0,0033806 & 1 & $-127,7197$ & 0 & $2,97571 \mathrm{e}-5$ & 2,48533 & 0,9972 \\
\hline \multirow{2}{*}{ MT28 } & $A \rightarrow V$ & $-31,49497$ & 0 & 0,0034044 & 1 & $1,43151 \mathrm{e}-20$ & 18,43535 & 3,32589 & 0,50226 & 0,9992 \\
\cline { 2 - 11 } & $A \rightarrow \alpha$ & 388,8377 & 0 & 0,013898 & 1 & $-279,8351$ & 0 & $3,03451 \mathrm{e}-5$ & 2,39054 & 0,9987 \\
\hline \multirow{2}{*}{ VT28 } & $A \rightarrow V$ & $-18,39349$ & 0 & 0,0011365 & 1 & $1,07831 \mathrm{e}-29$ & 27,80117 & 7,21946 & 0,44622 & 1,0000 \\
\cline { 2 - 11 } & $A \rightarrow \alpha$ & 432,6838 & 0 & 0,013998 & 1 & $-292,6369$ & 0 & $2,81509 \mathrm{e}-5$ & 2,35183 & 0,9995 \\
\hline CT28 & $A \rightarrow V$ & 5,66721 & 0 & 0 & 0 & $4,70819 \mathrm{e}-70$ & 34,06274 & 0 & 0 & 1,0000 \\
\hline
\end{tabular}

Как показано ранее, в дальнейшем тип леса СТ28 из анализа выпадает.

Таблица 6

Параметры закономерности влияния возраста на запас и долю оставляемой $<28$ см части сосняков

\begin{tabular}{|c|c|c|c|c|c|c|c|c|c|c|}
\hline \multirow{2}{*}{$\begin{array}{c}\text { Тип } \\
\text { леса }\end{array}$} & \multirow{2}{*}{$\begin{array}{l}\text { Связь } \\
x \rightarrow y\end{array}$} & \multicolumn{4}{|c|}{ Первая составляющая } & \multicolumn{4}{|c|}{ Вторая составляющая } & \multirow{2}{*}{$\begin{array}{l}\text { Коэф. } \\
\text { корр. }\end{array}$} \\
\hline & & $a_{1}$ & $a_{2}$ & $a_{3}$ & $a_{4}$ & $a_{5}$ & $a_{6}$ & $a_{7}$ & $a_{8}$ & \\
\hline \multirow{2}{*}{ OMT28 } & $A \rightarrow V$ & 0,23424 & 2,17758 & 0,031747 & 4 & 0 & 0 & 0 & 0 & 0,9705 \\
\hline & $A \rightarrow \alpha$ & 100 & 0 & 0 & 0 & $-4,50093 \mathrm{e} 7$ & 35,50585 & 71,30058 & 0,19742 & 0,9969 \\
\hline \multirow{2}{*}{ MT28 } & $A \rightarrow V$ & 0,0038938 & 5,18989 & 1,40833 & 0,47975 & 0 & 0 & 0 & 0 & 0,9898 \\
\hline & $A \rightarrow \alpha$ & 100 & 0 & 0 & 0 & $-2,91574 \mathrm{e}-21$ & 20,85981 & 6,23757 & 0,42848 & 0,9927 \\
\hline \multirow{2}{*}{ VT28 } & $A \rightarrow V$ & 2,14698 & 1,49599 & 1,46821 & 0,00028212 & $-1,17623 \mathrm{e}-26$ & 15,79480 & 0,0044042 & 1,61268 & 0,9854 \\
\hline & $A \rightarrow \alpha$ & 100 & 0 & 0 & 0 & $-5,04922 \mathrm{e}-50$ & 29,00680 & 0,0095748 & 1,61551 & 0,9294 \\
\hline
\end{tabular}

В брошюре [3] технология извлечения кругляка из сосняков не рассматривается. Но мы полагаем, что наилучшими способами являются выборочные рубки деревьев с толщиной на высоте $1,3 \mathrm{м} \geq 28$ см.

Причем в 1916-1918 гг. сортиментная заготовка длинномерных бревен при применении конно-воловой тяги была экологически оправданной: оставляемые на доращивание сосны толщиной $<28$ см не повреждались. Введение трелевки тракторами заставила в СССР везде и всюду применять способы сплошных рубок древостоев.

Поэтому закономерности из таблицы 6 в машинизированных технологиях извлечения из леса кругляка стали неприменимыми, но к ним нужно всячески стремиться, что и станет в XXI веке основным направлением диверсификации лесной промышленности России.

По данным таблицы 6 остаточный запас в сосняках характеризуется одним биотехническим законом [4-8], но с сильными колебательными возмущениями по сравнению с таблицей 1 хода роста сосняков Южной Финляндии по состоянию на 1916-1918 гг. Таким образом, любое извлечение крупномерного кругляка из леса является истощительным процессом.

Тип леса VT является полным по параметрам, - в динамическом ряду извлекаемый запас расположен внутри хода роста сосняков по 77 пробным площадям [3, c.34]. 
Волновые закономерности типа VT. Они с учебтгом волновых составляющих графически показаны на рисунке 5.

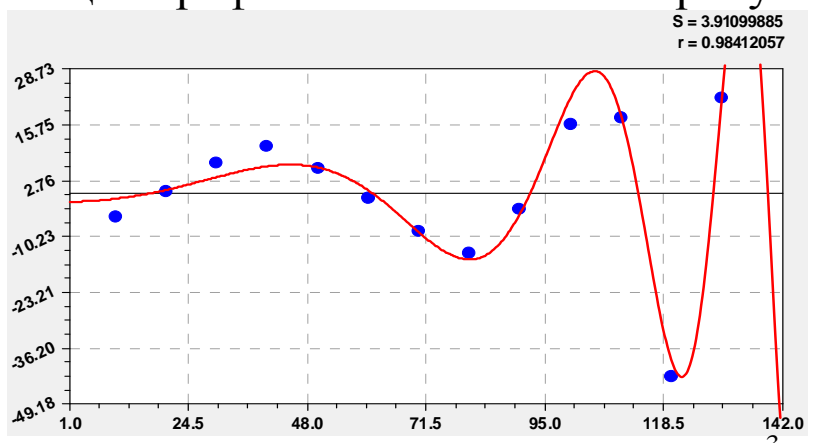

График волновой закономерности запаса, $\mathrm{m}^{3} / \Gamma \mathrm{a}$
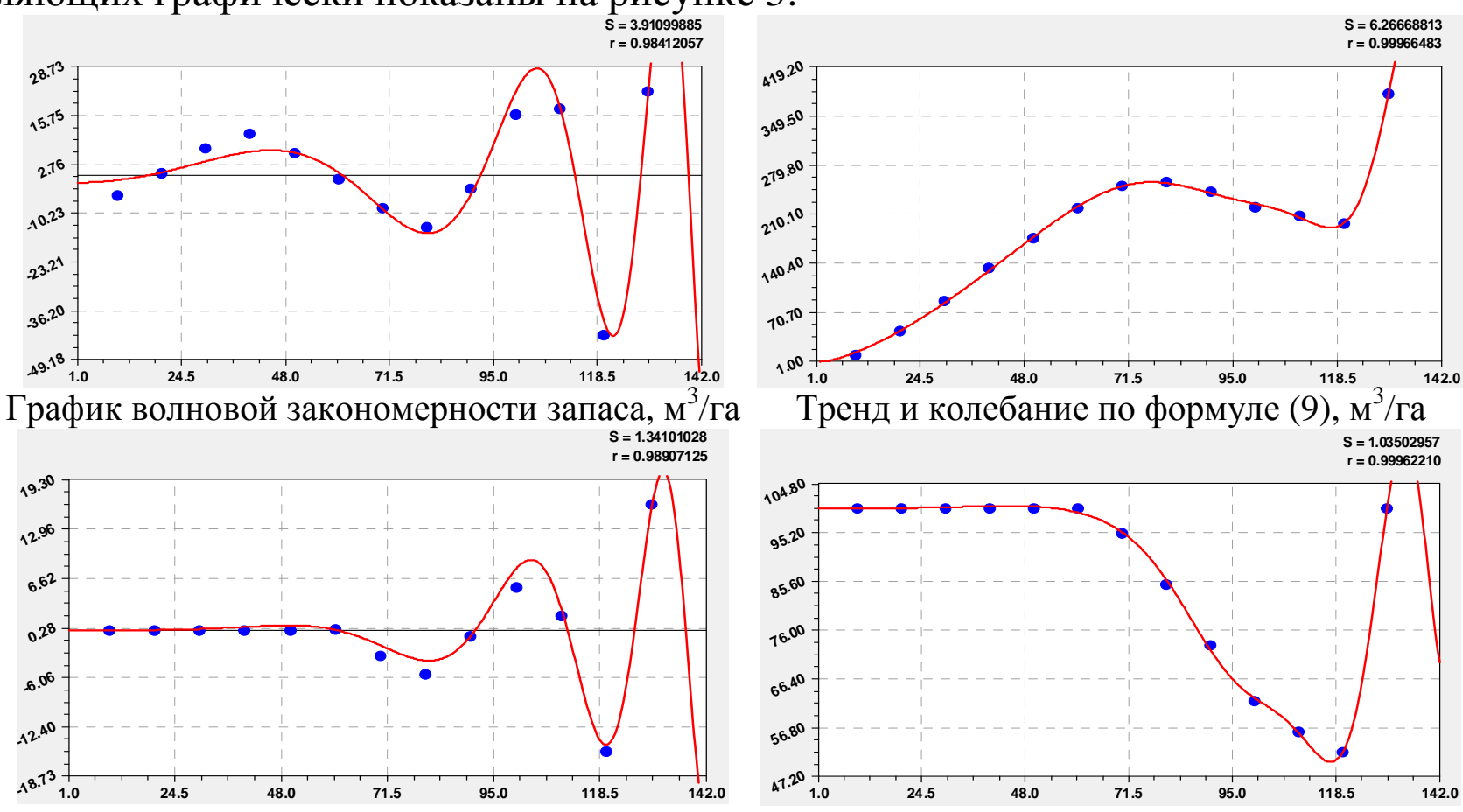

Тренд и колебание по формуле (9), $\mathrm{m}^{3} /$ га

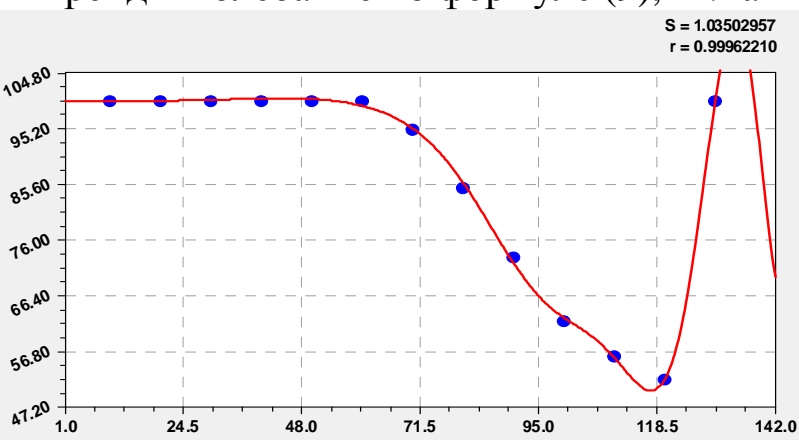

График волновой закономерности доли запаса, \% Тренд и колебание по формуле (10), \%

Рис. 5. Волновая динамика остаточного запаса древесины и её доли в сосняках типа VT

Графики на рисунке 5 характеризуются трехчленными уравнениями:

$$
\begin{gathered}
V_{<28}=V_{1}+V_{2}+V_{3}, \\
V_{1}=2,14298 A^{1,50046} \exp \left(-1,47004 A^{0,00028212}\right), \\
V_{2}=-1,26281 \cdot 10^{-26} A^{15,80656} \exp \left(-0,0044501 A^{1,61268}\right), \\
V_{3}=\mathrm{A} \cos (\pi A / \mathrm{P}-5,70715), \mathrm{A}=-2,15150 \exp (0,025658 A), \\
\mathrm{P}=48,16845-0,00089105 A^{2,04233},
\end{gathered}
$$

где А - амплитуда (половина) колебания остаточного запаса в сосняках, причем это возмущение вызвано человеком, составившим таблицы хода роста и объемы извлечения из леса кругляка, а при наличии фактических данных возмущение покажет поведение лесозаготовителей, Р - полупериод колебательного возмущения остаточных сосняков, лет;

$$
\begin{gathered}
\alpha_{228}=\alpha_{1}+\alpha_{2}+\alpha_{3}, \\
\alpha_{1}=100, \alpha_{2}=-9,32624 \cdot 10^{-50} A^{28,87210} \exp \left(-0,0084237 A^{1,64234}\right), \\
\alpha_{3}=\mathrm{A} \cos (\pi \mathrm{A} / \mathrm{P}+1,12869), \mathrm{A}=-2,19572 A^{3,31087}, \mathrm{P}=52,77683-0,0037749 A^{1,79067} .
\end{gathered}
$$

В обоих уравнениях период волнения сокращается, начиная при условии $A=0$ от значений $2 \times 48,17 \approx 96$ лет для объема древесины и 106 лет для доли оставляемого запаса.

Таким образом, по исходным данным лесного плана лесного предприятия, по таблицам хода роста сосняков и изъятия из них стволовой древесины заданных размеров, для проведения выборочных рубок деревьев можно выявлять закономерности поведения составителей этих таблиц. А по данным лесной ин- 
вентаризации, по остаточным запасам древесины после проведения выборочных рубок деревьев, вполне можно выявить закономерности поведения персонала лесозаготовительных предприятий и определить нарушения в долгосрочном технологическом режиме воспроизводства сосняков и пользования ими лесами на кругляк.

Заключение. Мировая динамика лесопользования [4] убедительно доказывает, что во всех странах мира преобладающей является извлечение из леса кругляка. Именно доктрина кругляка снижает площадь и качество древостоев. Другие виды пользования лесными полезностями в лесной науке как бы и не существуют. Ограничение лесов по площади в пределах национальной территории заставили Финляндию, и в особенности Японию, уже с 70-х годов XX века коренным образом повысить «максимальное извлечение всех видов дохода от лесов» (четвертая цель лесного кодекса СССР от 1923 г.) при резком снижении собственного производства кругляка $[5,6]$. Национальные леса в этих странах функционально становятся национальными парками. К этому стремятся США (с 1960 г.) и Китай (с 1970 г.) [7].

Поэтому нужны новые методы измерений и анализа, выявления биотехнических закономерностей у извлекаемой на кругляк и не извлекаемой фактической части у сосняков.

\section{Литература}

1. Даль В.И. Толковый словарь русского языка. М.: Изд-во Эксмо, 2006. $736 \mathrm{c}$.

2. Избранные труды Г.Ф. Морозова / Сост. М.Д. Мерзленко. М.: МГУЛ, 2004. $168 \mathrm{c}$.

3. Каяндер А.К. І. Сущность и значение типов леса. II. Различие в учениях о типах леса (Каяндера, Морозова и Сукачева). М.: Гослестехиздат, 1933.50 с.

4. Мазуркин П.М. Лесоаграрная Россия и мировая динамика лесопользования. Йошкар-Ола: МарГТУ, 2007. 334 с.

5. Мазуркин П.М. Осознанные модернизации в лесном деле Японии и Финляндии // Международный журнал прикладных и фундаментальных исследований. № 8. 2010. С.29-41.

6. Мазуркин П.М. Осознанные повороты в лесном деле Японии // Современные наукоемкие технологии. № 7. 2010. С.19-32.

7. Мазуркин П.М., Автономов А.Н. Осознанный поворот в лесном деле Китая // Успехи современного естествознания. 2008. № 11. С.103-107.

8. Мазуркин П.М., Бедертдинов Э.Н. Метод анализа многолетней динамики заготовки кругляка // Успехи современного естествознания. 2008. № 11. C.67-72.

9. Морозов Г.Ф. Учение о лесе / Изд. 2-е, просм. В.В. Матренинским. Л.: $1925.385 \mathrm{c}$.

10. Орлов М.М. Общие основания для лесного хозяйства. СПб: 1903. 55 с. 